\title{
Correspondence
}

\section{Saddened and concerned}

I was saddened to read the correspondence from Professor Poole and others. ${ }^{1}$ Surely members of the College must know that when bodies like the General Medical Council and the National Health Service issue guidelines and regulations, the focus is on acute services. The only exception to this in recent years has been the particular framework for mental health services. We now have the latest initiative for mental health services, New Horizons, which envisages working with housing, education and employment agencies. Are the authors concerned about professional boundaries between these agencies?

The Royal College of Psychiatrists' Spirituality and Psychiatry Special Interest Group is interested in a patient's belief system and background, and only marginally in the belief system of the clinician. If a patient is to be treated holistically (and I cannot imagine that any of the signatories would demur from this), then a person's culture, religious and faith background have to be addressed and, more importantly, be part of the diagnostic process.

There is a distinction to be made between healthy and unhealthy belief systems and this distinction is reached through the diagnostic process. Religion like many other areas of human life and experience lends itself to delusions, which can be part of an unhealthy belief system. Surely Professor Poole and his colleagues would agree and would also accept that healthy spirituality is part of a person's very being? It is for this reason that I hope he and his colleagues will want to support the Special Interest Group in its work.

1 Poole R, Higgo R, Strong G, Kennedy G, Ruben S, Barnes R, et al. Concerns over professional boundaries remain unresolved. Psychiatrist 2010; eLetter (http://pb.rcpsych.org/cgi/eletters/34/2/639866).

The Venerable Arthur Hawes Archdeacon of Lincoln (retired), Co-Chair of the National Spirituality and Mental Health Forum, Chair of the Church of England Mental Health Advisory Group, Training Consultant with the Lincolnshire NHS Foundation Trust, UK, email: arthur.hawes@yahoo.co.uk doi: $10.1192 / p b .34 .6 .257$

\section{Spirituality and boundaries in psychiatry}

Poole et al ${ }^{1}$ appear to be reproving the Spirituality and Psychiatry Special Interest Group for neither endorsing nor refuting their stated opinion that spiritual and religious practices are breaching professional boundaries. They begin by taking issue with the views of Professor Koenig ${ }^{2}$ (a paper to which four members of the Group Executive Committee have also made a considered response ${ }^{3}$ ), further citing General Medical Council (GMC) guidance ${ }^{4}$ that, (1) doctors should not discuss their personal beliefs with patients unless these beliefs are directly relevant to patient care, and (2) doctors should not impose their beliefs on patients.

Concerning the GMC guidance, since the Group agrees with both points, it seems there is no argument to be had on this front. As for the Group's response to Professor Koenig's paper, we have highlighted why we think the relationship of spirituality (including secular spirituality) to mental health is important for every psychiatrist to be aware of. ${ }^{3}$ Although we advocate extreme caution in the matter of prayer with patients because of the complex boundary issues raised, we do not see this as something to be ruled by fiat.

Enquiring about a patient's spirituality can be extremely helpful. Psychiatrists routinely ask about other central aspects of patients' lives such as sexuality which might influence, and be influenced by, psychopathology. There is evidence that religious and spiritual beliefs may similarly affect psychological functioning both positively and negatively and that those beliefs may, in turn, be influenced by mental illness. A tactful enquiry about patients' belief systems frequently reveals information that may be helpful in understanding coping strategies. Atheism, as a belief system, is no exception.

There is evidence that many patients want to be able to share with mental health professionals their spiritual and religious beliefs and values, to which they frequently turn when under stress. ${ }^{5}$ Indeed, by enabling such issues to come up for discussion, the psychiatrist may well be facilitating the therapeutic relationship. ${ }^{6}$

Mental illness causes fragmentation of the self and finding healing or wholeness (the root of the words is the same) is intrinsic to recovery. This has been endorsed by the World Health Organization: 'Patients and physicians have begun to realise the value of elements such as faith, hope and compassion in the healing process'. ${ }^{7}$

Given that religious and spiritual beliefs are important for many patients and that for these patients showing interest in, and concern for, their beliefs may have therapeutic value, we feel it is appropriate to routinely enquire about such beliefs. As with all aspects of the clinical consultation, this needs to be done with sensitivity and tact. If a patient does not want to discuss such issues, the subject is gently dropped - there is no question of putting anyone under pressure. The agenda is set by the patient.

We see it as important that enquiry should be carried out in a manner that conveys openness to every kind of belief humanist, secular, spiritual and religious alike. Patients who have experienced trauma with religious or spiritual organisations (sometimes associated with sexual abuse) may be fearful of speaking out. The psychiatrist who conveys concern, empathy and understanding will give the best chance of finding out which spiritual concerns may need understanding in order to enhance a good therapeutic outcome. The same GMC guidance on personal beliefs and medical practice cited by Poole et al goes on to state:

For some patients, acknowledging their beliefs or religious practices may be an important aspect of a holistic approach to their care. Discussing personal beliefs may, when approached sensitively, help you to work in partnership with patients to address their particular treatment needs. You must respect patients' right to hold religious or other beliefs and should take those beliefs into account where they may be relevant to treatment options.

Last, we should make clear that the Spirituality and Psychiatry Special Interest Group is precisely that - a special interest 
group. Its function is neither prescriptive nor prohibitive. We would no more advocate proselytising than see spiritual concerns ousted from the clinical consultation.

We wish to make clear that we welcome the debate to which Poole et al are contributing and look forward to further discussion when Professor Poole will be talking at the Group's programme in October 2010 on 'Intolerant secularisation'. We do not look for uniformity of opinion, but we do hold that every viewpoint is worthy of consideration and respect.

Christopher C. H. Cook is Consultant Psychiatrist, Tees, Esk and Wear Valleys NHS Foundation Trust, and Professorial Research Fellow, Department of Theology and Religion, Durham University, email: c.c.h.cook@durham.ac.uk; Simon Dein is Consultant Psychiatrist, Princess Alexandra Hospital, and Senior Lecturer, University College London; Andrew Powell is former Consultant Psychotherapist and Honorary Senior Lecturer,

Oxfordshire Mental Healthcare Trust and University of Oxford; Sarah

Eagger is Consultant Psychiatrist, Central and North West London NHS

Foundation Trust, and Senior Lecturer, Imperial College London.

1 Poole R, Higgo R, Strong G, Kennedy G, Ruben S, Barnes R, et al. Concerns over professional boundaries remain unresolved. Psychiatrist 2010; eLetter (http://pb.rcpsych.org/cgi/eletters/34/2/63\#9866).

2 Koenig HG. Religion and mental health: what should psychiatrists do? Psychiatr Bull 2008; 32: 201-3.

3 Dein S, Cook CCH, Powell A, Eagger S. Religion, spirituality and mental health. Psychiatrist 2010; 34: 63-4.

4 General Medical Council. Personal Beliefs and Medical Practice - Guidance for Doctors. GMC, 2008.

5 Faulkner A. Knowing Our Own Minds. Mental Health Foundation, 1997.

6 McCord G, Gilchrist VJ, Grossman SD, King BD, McCormick KF, Oprandi AM, et al. Discussing spirituality with patients: a rational and ethical approach. Ann Fam Med 2004; 2: 356-61.

7 World Health Organization. WHOQOL and Spirituality, Religiousness and Personal Beliefs: Report on WHO Consultation. WHO, 1998.

doi: $10.1192 / \mathrm{pb} .34 .6 .257 \mathrm{a}$

\section{Divine intervention in mental health}

We thank Dein et al for opening up the debate about religion and its impact on mental well-being. This debate does not come a moment too soon.

We feel compelled to refute the suggestions that research unequivocally shows an association between religiosity and well-being. ${ }^{2}$ The research findings are wildly contradictory and it would be unreasonable to draw any firm conclusion on the basis of current knowledge. Furthermore, the research in this area is often biased, plagued by poor methodology (definitions of spirituality and religion are controversial, much variation exists between different faith groups, 'hidden' supportive measures of any community tend to be responsible for wellbeing rather than religion per se) and the research is almost invariably carried out by groups of researchers that have a vested interest in showing positive results for religiosity. The last point also applies to Dein and colleagues as they represent the Royal College of Psychiatrists' Spirituality and Psychiatry Special Interest Group. None of these points of contention is raised in the article.

In our personal experience we can come to think of a handful of patients that indeed seemed to have been consoled by religious beliefs, but hundreds of patients who have been tormented by fear of having transgressed some Bronze Age dogma about sexuality, having sinned in other ways or simply having taken their God's name in vain. A common sight on psychiatric wards is frightened patients shivering with fear when they hear what they perceive to be God's, not to mention Satan's, voice in their hallucinations. Some studies report that patients with schizophrenia and religious beliefs do indeed have worse long-term outcomes than patients with nonreligious delusions. ${ }^{3}$ The rigid cognitive belief system that underpins religious ideology plays straight into delusional beliefs that cause endless anguish, for example, 'If I break my pact with God (e.g. divorcing a violent husband, having sex out of wedlock), He will punish me'. Meeting such patients gives the concept of being 'God fearing' a whole new dimension. This commonplace suffering seems to have escaped the authors entirely.

Dein et al complain that there is a gap between patients' and psychiatrists' level of religiosity, the patients being more religious. Initially, this observation begs the question of whether religion could be part of the complex set of aetiological factors that constitutes the pathogenesis of mental illness in the first place and perhaps maintains it. Unquestioned belief in authorities always spells trouble, which recent events in the Catholic Church so amply exemplify. Some perturbed patients may find the certainties of religion tempting, but at what cost? Nevertheless, a good point is made that we must enquire more about the patient's religious beliefs as they can have a profound impact on lives from an early age. Yes, just think of the consistent mistreatment of women and children in some religions, beliefs in utterly unverifiable concepts (walking on water, miracles, angels with wings, devils, etc.) and the survival of your own death through an immortal soul, going to Heaven if you have been good but going to Hell if you have not. No wonder if you have a fragile mind that religious beliefs can push you over the edge.

We remind Dr Dein and his colleagues that instead of promoting private views, however strong and well meant they are, our traditional mandate as doctors is 'first of all, do no harm'. A more important question than whether the psychiatrist should pray with the patients or not - consider what this would entail if you had a Satanist under your care seems to us to be how religious groups systematically have targeted vulnerable psychiatric patients in an attempt to boost flagging numbers of their congregations. It is a despicable practice that pretends to offer lonely people a 'new family' for the 'minor cost' of believing in, and sometimes financially supporting, various belief systems of a more or less outrageous nature. It may be advantageous to a lonely or marginalised individual to find a ready-made group of accepting individuals with whom to associate, but religious groups do not have the monopoly on providing such solace. The issue of compassion is certainly not just the preserve of religious orders. So no, it is not 'time to move away from the old tendency to see religious and spiritual experiences as pathology'. But it is time to enquire in a respectful and gentle manner about patients' beliefs in general, not only religious ones, and for all, the psychiatrist should always remain the patient's foothold in a reality that often for them appears broken and fragile. Religious beliefs and practices may be helpful for some in terms of companionship and certainty, but clinical evidence indicates that for others 